\title{
OTITIS MEDIA WITH PURULENT MENINGITIS IN AN INFANT NINE DAYS OLD
}

\author{
BY
}

GLADYS H. DODDS, M.I., D.P.H.,

Assistant in the Obstetric Unit, University College Hospital, London.

Purulent meningitis arising from otitis media in very young infants is a rare condition. The case we record is the only one which has occurred in the Obstetric Hospital, University College Hospital, during the last four years. Cruickshank ${ }^{1}$ in his investigation of 800 neonatal deaths, (i.e., in infants up to 28 days old), found meningitis in 4 per cent. of the cases. He, however, does not describe any cases associated with otitis media.

The condition of otitis media in newly born and young infants is well recognized, particularly by French observers.

Duverne $y^{2}$ in 1683 was the first to point out the presence of fluid in the middle ear in these infants. Schmalt $\%^{3}$, Lesser ${ }^{4}$ and Lenhardt ${ }^{5}$ drew attention to the presence of vernix caseosa and liquor amnii in the middle ear. $K^{\circ}$ pper $^{6}$ in 18.57 was the first to note the presence of pus. In a number of infants aged less than 25 days he noted an empty space 6 times and the presence of Huid in 18 cases, in 4 of which the fluid had the character of pus. Schwartze ${ }^{7}$, Roosa ${ }^{8}$, de Troelts $\mathrm{ch}^{9}$, Parrot ${ }^{10}$ and $\mathrm{W}^{\prime}$ endt ${ }^{11}$ were also among the early observers of this condition and since their time numerous cases have been recorded.

There is disagreement whether the otitis media is a primary or secondary infection. Hartmann ${ }^{12}$, Byfield ${ }^{13}$, Preysing ${ }^{14}$, McDougal and Knaker ${ }^{15}$, Floyd ${ }^{16}$, Alden and Lyman ${ }^{17}$, Pluder ${ }^{18}$ and other authors note the co-existence of gastrointestinal or respiratory disease with otitis media. These observers believe that the otitis precedes the enteritis or respiratory disease in certain cases. They believe that an aggravation of the otitis causes an aggravation of the enteritis. They show the necessity for paracentesis and cite cases where clinical signs have disappeared when paracentesis is performed. On the other hand, Lenhartz ${ }^{19}$, Veillard ${ }^{20}$ and others who also note the same association of otitis media with gastro-enteritis or respiratory disease, believe that the otitis is an agonal infection.

Mahu and Chomé ${ }^{21}$ report a case of still-born foetus, where they believe the middle ear was infected during labour. The mother was a primipara ; presentation was breech; duration of labour 48 hours; membranes ruptured at commencement of labour. On post-mortem examination the middle ear was found infected. Cultures were taken from the middle ear. According to Mahu and Chomé the anatomical state of the ear in the fœtus and the infant at birth is such that there is an anatomical predisposition to infection. The Eustachian tube has not yet reached its full development and is short and wide. The tympanic cavity is filled by a gelatinous material which opposes no 
obstacle to the penetration of liquids and offers on the other hand an excellent culture medium to micro-organisms which can penetrate. The infections occur at the moment of aspiration and deglutition. When in the process of birth the fotus inspires, the contents of the maternal vagina move towards the fœtal lung; but if the movement of deglutition intervenes the contents of the maternal vagina are forced towards the middle ear, penetrate the gelatinous material, dislocate it and gradually transform the tympanic cavity into a real cavity.

The rarity of perforation of the drum is noted by all observers. Arbeltier ${ }^{22}$ showed that in a series of 125 infants aged 1 to 20 months in l'Hôpital Bretonneau, 11 had a discharge from one or other ear, i.e., 8.8 per cent. In the same hospital when a systematic examination of the ears was made in a series of 102 infants of the same age period, 72 infants were found to have otitis, which was often bilateral, i.e., 72 per cent. In a series of 150 infants examined in the out-patient department of the same hospital 33 per cent. had otitis. Alden and Lyman ${ }^{23}$, in a series of 70 consecutive autopsies on infants who died of vomiting and infantile diarrhœa, found suppuration in the middle ear in all cases. Thirty cases had been diagnosed during life.

The absence of meningitis in cases of otitis media in newly born infants is also noted. Veillard ${ }^{20}$ in a series of 80 cases of otitis media did not meet with one case. Coeppert ${ }^{24}$ has stated that the danger of meningitis and septicæmia as a result of otitis is less in infants than in adults. Netter ${ }^{25}$ found bilateral otitis media in 20 cases; post mortem, among these cases there were two instances of suppurative meningitis. Thrombosis of the inferior petrosal sinus is also rare and the only record I have been able to find is one by Renaud ${ }^{26}$ in a six weeks old child.

\section{Case report.}

The importance and rarity of otitis media in the causation of death in the new-born seem sufficient justification for recording the following case.

The mother, a 4-para aged 35 years, had a normal pregnancy and had been under observation at the ante-natal clinic during the last two months of her pregnancy. Her Wassermann reaction was negative. She was admitted to the Obstetric Hospital, Cniversity College Hospital, on September 11th, 1930. The history of the labour was as follows : labour pains commenced at 5 a.m., September 11th, membranes ruptured at the same time. The child, full time, was delivered spontaneously at 1.25 a.m., September 1:2th. The presentation was left occipitoanterior. Weight at birth was $3,650 \mathrm{grm}$.

During the first 5 days the baby appeared perfectly normal; temperature, pulse and respirations were normal. On 3rd and 4th days the infant gained in weight. On the 6 th day the cord separated, the temperature rose to $100 \cdot 2^{\circ}$ and respirations were rapid, but the infant took his feeds. On the 7 th day the temperature was $101^{\circ}$, respirations 40 , and feeds were not being well taken. 'The mother's milk was expressed and given in a bottle. On the 8 th day the temperature was $101^{\circ}$, and respirations irregular, ('heyne Stokes in type. The infant was slightly jaundiced and refused feeds; he was not sick and his stools were normal. The thorax was examined but no abnormal physical signs were discovered. There was no head retraction; the fontanelle was not tense. There was no discharge from the ears. On the 9 th day the temperature was $101^{\circ}$ and in the morning the general condition seemed better and he took breast milk occasionally, but in the afternoon he had several attacks of dyspnna, refused to take feeds and died at 11 p.m. 
Post-mortem examination.-Full time male infant, slightly jaundiced; no evidence of emaciation ; umbilical cord separated and no evidence of sepsis around the scar. Weight of infant was $3,050 \mathrm{grm}$., length $51 \mathrm{~cm}$. The thymus was very pale but normal in size. The lungs were fully aerated and congested, but there was no consolidation and no naked eye evidence of pneumonia. Microscopically the lungs were congested and in one area there was a slight small celled infiltration, but no exudate. The heart was normal in size, but looked paler than normal and fatty. There was no valvular lesion. Nothing abnormal was noted in the abdominal cavity beyond the toxic appearance of all the organs. The umbilical scar appeared healthy and on sectioning there was no evidence of infection.

On examining the brain there were found marked congestion of the meninges and a considerable amount of greenish pus on all surfaces of the cerebral hemispheres, but most marked round the base of the brain. The right ear showed no abnormality; the left ear, middle ear and surrounding bone were soft and filled with greenish pus. Cultures were taken from the brain and middle ear and a profuse mixed growth was obtained. The causal organism could not be isolated.

\section{Summary.}

A case of primary otitis media with purulent meningitis in a newly born infant is reported.

\section{REFERENCES.}

1. Cruickshank, J. N., Med. Res. Council, Sp. Rep., Lond., 1930, 145.

2. Duverney, quoted by Veillard.

3. Schmaltz, H., Arch. d. Heilk., 1877, XII, 250.

4. Lesser, quoted by Veillard.

5. Lenhardt, Thése Paris, Paris, 1887, 16.

6. Kopper, quoted by Veillard.

7. Schwartze, H., Arch.f. Ohrenh., 1864, 202.

8. Roosa, St. J., Am. J. Med. Sc., Philad., 1867, 402.

9. de Troeltsch, quoted by Veillard.

10. Parrot, M. J., Bull. et mém. Soc. Méd. d. hэp., Paris, 1869, VI, 82.

11. Wendt, Arch. d. Heilk., 1873, 97.

12. Hartmann, A., Ztschr. f. Ohrenh., 1898, XXIV, 1.

13. Byfield, A. H., Abt's Pediatrics, III, 786.

14. Preysing, H., quoted by D. M. Lierle, Ann. Oto\%. Rhin. \& Laryng., St. Louis, 1927, XXXVI, 604.

1.). McDougal \& Knaker, Laryngoscspe, St. Louis, XXXIII, 936.

16. Floyd, Arch. Otolaryng., Chicago, I, 411.

17. Alden, A. M., \& Lyman, H. W., Trans. Am. Laryngol, Rhin. Otol. Soc., 1925, 67.

18. Pluder, quoted by Arbeltier.

19. Lenhartz, loc. cit.

20. Veillard, G. P., Thése Paris, Paris, 1899, 491.

21. Mahu, \& Chomé, E., Gynéc. et Obstét., Paris, 1922, VI, 313.

22. Arbeltier, R., Thése Paris, Paris, 1922, 146.

23. Goeppert, quoted by Veillard.

24. Netter, Société de Biol., 1889, 305.

25. Renaud, M., Bull. et mém. Soc. méd. d. hop. de Paris, Paris, 1921, XLV, 1326. 